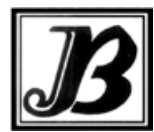

J. Bio-Sci. 24: 55-65, 2016

ISSN 1023-8654

http://www.banglajol.info/index.php/JBS/index

\title{
IN SILICO ANALYSES OF HUMAN COLLAGEN PROTEIN FUNCTION PREDICTION
}

\author{
MS Ahmed ${ }^{1 *}$, M Kamruzzaman $^{2}$, MM Rana ${ }^{1}$, Z Akond $^{1}$ and MNH Mollah ${ }^{1}$ \\ ${ }^{1}$ Bioinformatics Lab., Department of Statistics, University of Rajshahi, Bangladesh \\ 2Institute of Bangladesh Studies, University of Rajshahi, Bangladesh
}

\begin{abstract}
Collagen is the extracellular matrix protein in the several connective tissues in the human body. It is an important component for mediating cell-cell interactions and pathological conditions in human body. In this study we perform the analysis of physiochemical properties and investigate the functional characteristics of human collagen proteins. Also investigate the functional protein groups by the statistical analysis. The collagen protein family consisting 28 members in human which are involving in the complex structure of protein. The protein function, protein sequence properties, domain composition, phylogenetic and protein-protein interaction (PPI) networks analysis of human collagen alpha-1 protein sequences are implemented by the online bioinformatics tools which are currently available. Based on the PCA analysis amino acid composition, features of collagen protein sequences are divided into two supreme influential functional groups such as collagen 12,14, 20 formed one group and the rest of others formed another group. The protein-protein interaction network study using STRING showed that top interacting score of functional group proteins $0.952,0.939$ and 0.929 . The most common functional domain of collagen proteins are VWC, C4, LamG, VWA, KU, C1Q, TSPN and FN3. Physicochemical, functional and phylogenetic classification can give extensive information of protein's structure and function. The depiction of alpha-1 chains of collagen protein family in human collagen 12, 14 and 20 as a prospective protein cluster. These three proteins are possess, low glycine and proline, very high aliphatic index and a close evolutionary relation in the human skin.
\end{abstract}

Key words: Collagen protein sequences, k-means clustering, PCA, phylogenetic tree, PPI network, protein domain structure

\section{Introduction}

The extracellular matrix (ECM) is consisting of collagens, proteoglycans, glycoproteins and proteases. The extracellular matrix of connective tissues represents a complex alloy of variable members of diverse protein families defining structural integrity and various physiological functions. It is the main component of connective tissue and makes up from $25 \%$ to $35 \%$ of the whole-body protein content. Collagen Type I protein found in bone, skin, muscles and walls of blood vessels in human body (Järveläinen et al. 2009). Neighboring a substantial volume of cells the ECM is an intricate network of macromolecules. For the multiple processes such as cell migration, cell-cell interaction and cell proliferation these components play vital role (Bowers et al. 2010). The collagen protein is a triple helical structure of polypeptide chains, commonly known as the alpha chains. The common sequence pattern of triple helix is "Gly-X-Y" (Kadler et al. 1996). The stability of the helical structure depends on the presence of glycine as every third residue and being other property of the smallest amino acid. Any amino acid can be taken instead of $X$ and $Y$ but frequently occupied by the proline residue. Every mature active collagen protein molecules were shown that the peptidases form of pro-peptides present at the $\mathrm{N}$ and $\mathrm{C}$ terminal. The genetically distinct 28 members

*Author for correspondence: shakil.statru@gmail.com 
found in human biological system. The collagen family is a large and a complex protein family in the proteome (Gelsea et al. 2003). The genomics, proteomics and the computational biology is an evolving field that helps to understand the concealed information of a protein structure (Nassa et al. 2012). In this study reports a qualified portrayals of alpha-1 sequences of human collagen using statistical methods and biocomputational tools. Three alpha chains present in collagen alpha-1 was pragmatic human collagen family. To analysis of physiochemical properties, functional group, phylogenetic classification, domain composition and PPI networks of human collagen using the amino acid sequence features. Objective of this research is to afford an intuition to various proteins features of collagen proteins and represent this large family. The presence of any nonconforming entrances in the collagen molecules for impending adherents to implicate the disease in collagen family (Bateman et al. 2009). Most of the previous studies are based on the wet lab experimental and it is very much time consuming, costly and laborious for identification of functional collagen proteins in the human skin. In this case we have suggested some in silico and statistical methods for functional analysis of collagen proteins. It might be reduced time and cost in comparison with experimental methods. This study might be helpful for biologists in stentorian of promote soundings on these complex molecules, interacting proteins, and functional domains for human diseases in collagen family.

\section{Materials and Methods}

\section{Collection of human collagen apha-1 sequences}

Human collagen family alpha-1 protein sequences of all 28 members were collected in FASTA format using the accession number provided for each collagen sequence from UniProtKB/ SWISS-PROT (http://expasy.org/sprot/) (Bairoch et al. 2000) protein database.

\section{Physiochemical Portrayal of Human Collagen Family}

Various features including the number of amino acids, molecular weight, theoretical isoelectric point (pl), amino acid composition (\%), number of positively (Arg + Lys) and negatively charged (Asp + Glu) residues, extinction co-efficient, instability index, aliphatic index and Grand Average of Hydropathicity (GRAVY) were computed using ExPASy's ProtParam tool by inputting the protein sequence in FASTA format (http://expasy.org/tools/protparam.html).

\section{Protein domain composition of human collagen family}

The protein domain composition and post translation sites prediction using SMART (http://smart.emblheidelberg.de/) (Letunic et al. 2012) bioinformatics tool also used to scan and identify all the known domain. To predict the nature and position in the selected alpha-1 protein sequences of the collagen family based on a profile and pattern search. The input protein sequence in FASTA format was used for a selected protein profile in the database.

\section{Multiple sequence alignment and phylogenetic analysis}

Multiple sequence alignment of the human alpha-1 collagen protein sequences were aligned using MEGA5.0 tools (Tamura et al. 2011), the sequence alignment algorithm was used ClustalW of protein sequences in FASTA format as the input data type. For a set of input sequences the best alignment was computed and all the identities. The phylogenetic tree or evolutionary tree was customary by constructing phylograms through recovery of the alignments using Neighbor Joining (NJ) method. 


\section{Protein-protein interaction (PPI) networks analysis}

The accurate prediction of protein functions is important for interacting residues with each other. This study used STRING (http://string-db.org/) a database of known and predicted protein interactions networks through physical and functional associations (Andrea et al. 2013). The input protein sequence was used in FASTA format for prediction of PPI networks.

\section{Statistical analysis of collagen protein sequences}

The analysis of amino acid functional group was used k-means clustering approach. To investigate the collagen protein functional group we used the multivariate statistical techniques principal component analysis (PCA), it is very much popular techniques in bioinformatics data analysis. In this paper, all the statistical analysis likes k-means clustering and PCA were done using R-packages(R 3.2.0) and MS Excel-2010.

\section{Results and Discussion}

The portrayals of human collagen alpha-1 extracellular matrix protein are most important for human skin. Collagen protein sequence physiochemical properties analysis was done by the ExPASy ProtParam online tools (Table 1). The highest aliphatic index is 79.61 of Col20 (Fig. 1a) was regarded as the thermostable and Col14 (77.67) and Col12 (75.45). The GRAVY values (Fig.1 b) indicate the range from -2 to +2 of proteins are positively related with the proteins being more hydrophobic (Kyteet al. 1982).

Table 1. Physiochemical properties of collagen protein family.

\begin{tabular}{|c|c|c|c|c|c|c|c|c|c|c|}
\hline $\begin{array}{l}\text { Collagen } \\
\text { Proteins }\end{array}$ & $\begin{array}{c}\text { Accession } \\
\text { number }\end{array}$ & $\begin{array}{c}\text { No. of } \\
\text { AA }\end{array}$ & $\begin{array}{c}\text { Molecular } \\
\text { weight }\end{array}$ & $\mathrm{pl}$ & $\begin{array}{c}\text {-ve } \\
\text { charged } \\
\text { residue }\end{array}$ & $\begin{array}{l}\text { +ve } \\
\text { charged } \\
\text { residue }\end{array}$ & $\begin{array}{l}\text { Extinction } \\
\text { Coefficient }\end{array}$ & $\begin{array}{c}\text { Instability } \\
\text { index }\end{array}$ & $\begin{array}{c}\text { Aliphatic } \\
\text { index }\end{array}$ & GRAVY \\
\hline Coll 1 & P02452 & 1464 & 138941.5 & 5.6 & 141 & 128 & 53495 & 30.43 & 37.98 & -0.788 \\
\hline Coll 2 & P02458 & 1487 & 141785.3 & 6.58 & 141 & 139 & 54525 & 25.21 & 40.03 & -0.803 \\
\hline Coll 3 & P02461 & 1466 & 138564.2 & 6.21 & 129 & 122 & 62225 & 30.18 & 37.31 & -0.797 \\
\hline Coll 4 & P02462 & 1669 & 1606147.7 & 8.55 & 128 & 138 & 61070 & 32.04 & 47.39 & -0.621 \\
\hline Coll 5 & P20908 & 1838 & 183559.8 & 4.94 & 225 & 168 & 98850 & 33.09 & 45.35 & -0.873 \\
\hline Coll 6 & P12109 & 1028 & 108529.4 & 5.26 & 139 & 114 & 64970 & 28.52 & 68.70 & -0.525 \\
\hline Coll 7 & Q02388 & 2944 & 295219.6 & 5.95 & 332 & 310 & 159140 & 32.07 & 61.86 & -0.625 \\
\hline Coll 8 & P27658 & 744 & 73364 & 9.62 & 37 & 60 & 38405 & 36.06 & 61.21 & -0.434 \\
\hline Coll 9 & P20849 & 921 & 91869.2 & 8.94 & 86 & 96 & 42565 & 32.61 & 56.13 & -0.658 \\
\hline Coll 10 & Q03692 & 680 & 66157.9 & 9.68 & 34 & 54 & 42290 & 25.95 & 51.94 & -0.556 \\
\hline Coll 11 & P12107 & 1806 & 181064.8 & 5.06 & 222 & 174 & 103765 & 30.81 & 44.91 & -0.859 \\
\hline Coll 12 & Q99715 & 3063 & 333146.7 & 5.38 & 366 & 313 & 334620 & 32.90 & 75.45 & -0.427 \\
\hline Coll 13 & Q5TAT6 & 717 & 69949.9 & 9.27 & 67 & 81 & 15970 & 31.44 & 52.87 & -0.765 \\
\hline Coll 14 & Q05707 & 1796 & 193515.4 & 5.16 & 211 & 160 & 179095 & 37.57 & 77.67 & -0.326 \\
\hline Coll 15 & P39059 & 1388 & 141720.1 & 4.90 & 155 & 95 & 76485 & 40.19 & 68.00 & -0.377 \\
\hline Coll 16 & Q07092 & 1604 & 157751.3 & 8.14 & 144 & 150 & 65370 & 35.88 & 50.73 & -0.671 \\
\hline Coll 17 & Q9UMD9 & 1497 & 150419.3 & 8.89 & 117 & 128 & 109015 & 45.25 & 55.47 & -0.573 \\
\hline Coll 18 & P39060 & 1754 & 178187.6 & 5.67 & 164 & 133 & 145185 & 48.57 & 61.72 & -0.467 \\
\hline Coll 19 & Q14993 & 1142 & 115220.7 & 8.57 & 116 & 124 & 63215 & 30.68 & 56.68 & -0.708 \\
\hline Coll 20 & Q9P218 & 1284 & 135830 & 8.27 & 119 & 123 & 132990 & 45.18 & 79.61 & -0.261 \\
\hline Coll 21 & Q96P44 & 957 & 99368.5 & 8.57 & 98 & 106 & 55655 & 33.28 & 69.14 & -0.517 \\
\hline Coll 22 & Q8NFW1 & 1626 & 161145.3 & 6.88 & 174 & 172 & 57965 & 34.00 & 53.28 & -0.715 \\
\hline Coll 23 & Q86Y22 & 540 & 51943.9 & 6.88 & 65 & 65 & 14355 & 30.81 & 50.69 & -0.829 \\
\hline Coll 24 & Q17RW2 & 1714 & 175496.3 & 8.46 & 162 & 170 & 73075 & 28.32 & 64.21 & -0.622 \\
\hline Coll 25 & Q9BXS0 & 654 & 64770.7 & 8.60 & 73 & 78 & 11835 & 24.85 & 47.19 & -0.919 \\
\hline Coll 26 & Q96A83 & 441 & 45381.1 & 7.02 & 40 & 40 & 40170 & 46.77 & 63.11 & -0.523 \\
\hline Coll 27 & Q8IZC6 & 1860 & 186892.3 & 9.83 & 136 & 196 & 81205 & 37.62 & 54.15 & -0.637 \\
\hline Coll 28 & Q2UY09 & 1125 & 116657.1 & 6.10 & 136 & 131 & 55195 & 24.18 & 61.42 & -0.66 \\
\hline
\end{tabular}


The collagen 20 GRAVY is -0.261 then we may state that it is most hydrophobic protein than others. From the table collagen 15, 17, 18, 20 and 26 are unstable (instability index $>40$ ) and rest of the proteins are stable (instability index <40), the all values of instability index shows in Fig. 1(c).The 14 collagens pl (Fig. 1d) are less than 7, Col26 is approximate equal to 7 and rest of the greater than 7; hence the 14 collagens are acidic, Col26 is neutral and others collagen proteins are basic (Lim 2006).

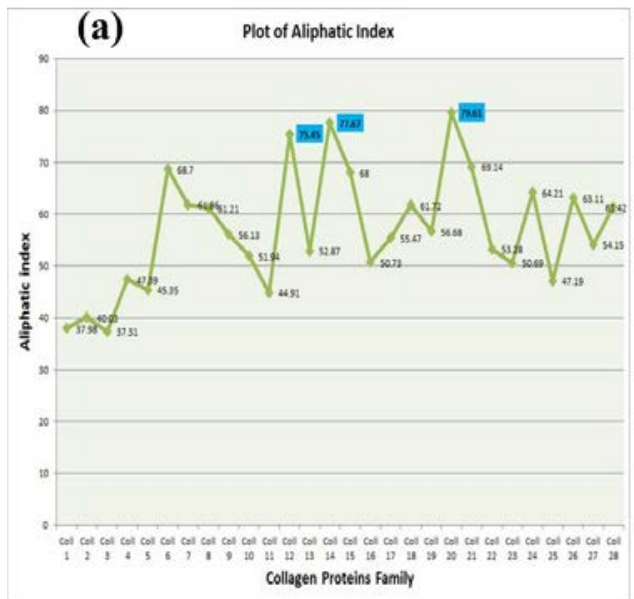

(c)

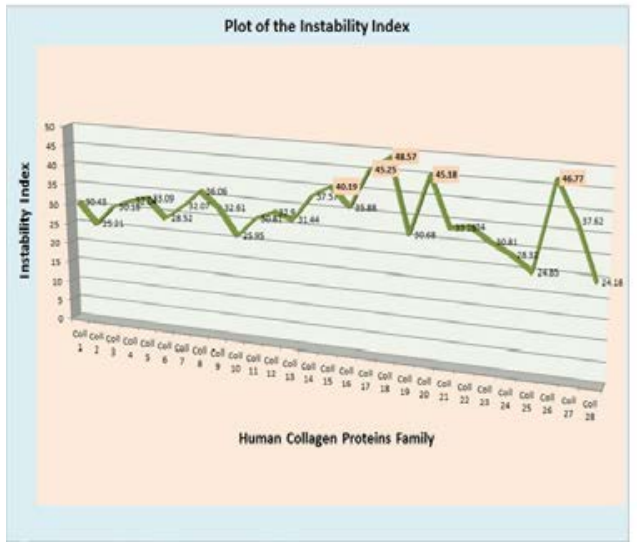

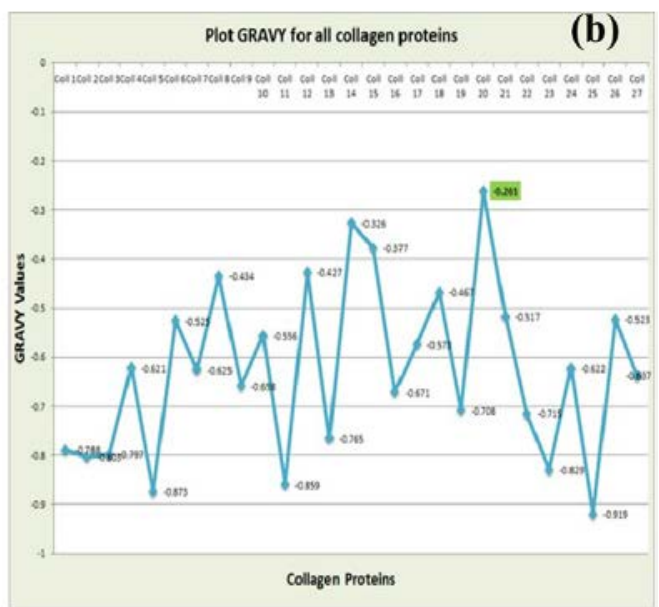

(d)

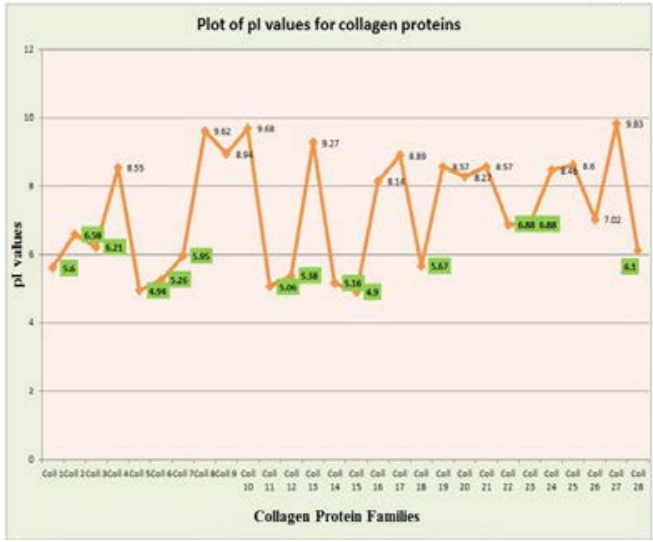

Fig. 1. (a) Aliphatic index, (b) GRAVY values, (c) Instability index and (d) pl values for all 28 human collagen alpha-1 families.

The common domain structure is COLFI (C-termini of Fibrillar collagen) of Coll1, Coll2, Coll3, Coll5, Coll11, Coll14 (Fig. 2) and the other domains are VWC (Von Willebrand factor type C), C4 (C-terminal tandem repeated), LamG (Laminin G), VWA (von Willebrand factor type A), FN3 (Fibronectin type-III), C1Q, TSPN (Thrombospondin N-terminal), FRI (Frizzled) and KU (BPTI/Kunitz family of serine protease inhibitors). From the Table 2 shown that Coll13, Coll15, Coll23, Coll25 and Coll26 proteins has no functional domain out of 28 human collagen protein families in the human skin. The maximum number of domains exists in the Coll12 (Evalues: $1.28 \mathrm{e}-8$ to $1.25 \mathrm{E}-78$ ), Coll14 (E-values: $4.22 \mathrm{e}-9$ to 0.214 ) and Coll20 (E-values: $19.6 \mathrm{e}-55$ to $2.89 \mathrm{e}-$ 33 ) proteins, those three protein domains are more functional activity of the ECM proteins. 
Table 2. Human collagen alpha-1 protein domains.

\begin{tabular}{|c|c|c|c|c|c|}
\hline $\begin{array}{l}\text { Collagen } \\
\text { Proteins }\end{array}$ & $\begin{array}{l}\text { Source } \\
\text { Gene }\end{array}$ & $\begin{array}{l}\text { Domain } \\
\text { Name }\end{array}$ & Start & End & E-value \\
\hline \multirow{3}{*}{ Col 1} & \multirow{3}{*}{ ENSG00000108821 } & VWC & 40 & 95 & 2.73E-20 \\
\hline & & COLFI & 1228 & 1464 & 1.25E-166 \\
\hline & & VWC & 34 & 89 & 7.42E-22 \\
\hline \multirow[t]{2}{*}{ Col 2} & \multirow[t]{2}{*}{ ENSG00000139219 } & COLFI & 1252 & 1487 & $6.46 \mathrm{E}-183$ \\
\hline & & VWC & 32 & 88 & $1.68 \mathrm{E}-20$ \\
\hline $\mathrm{Col} 3$ & ENSG00000168542 & COLFI & 1231 & 1466 & 1.15E-165 \\
\hline \multirow{3}{*}{ Col 4} & \multirow{3}{*}{ ENSG00000187498 } & C4 & 1445 & 1554 & $3.55 \mathrm{E}-66$ \\
\hline & & $\mathrm{C} 4$ & 1555 & 1668 & $3.70 \mathrm{E}-78$ \\
\hline & & TSPN & 39 & 230 & $6.53 \mathrm{E}-82$ \\
\hline \multirow[t]{2}{*}{ Col 5} & \multirow[t]{2}{*}{ ENSG00000130635 } & LamG & 98 & 229 & $6.50 \mathrm{E}-04$ \\
\hline & & COLFI & 1608 & 1837 & 1.06E-155 \\
\hline \multirow{6}{*}{ Col 6} & \multirow{3}{*}{ ENSG00000142156 } & VWA & 35 & 233 & 4.29E-31 \\
\hline & & VWA & 613 & 790 & $8.00 \mathrm{E}-31$ \\
\hline & & VWA & 827 & 1008 & $2.72 E-33$ \\
\hline & \multirow{10}{*}{ ENSG00000114270 } & VWA & 36 & 216 & $4.54 \mathrm{E}-53$ \\
\hline & & FN3 & 232 & 318 & $5.73 \mathrm{E}-11$ \\
\hline & & FN3 & 327 & 402 & $6.54 \mathrm{E}-06$ \\
\hline \multirow{7}{*}{ Col 7} & & FN3 & 415 & 493 & 9.11E-05 \\
\hline & & FN3 & 508 & 584 & $1.64 \mathrm{E}-06$ \\
\hline & & FN3 & 598 & 674 & $1.94 \mathrm{E}-08$ \\
\hline & & FN3 & 686 & 764 & 1.16E-11 \\
\hline & & FN3 & 776 & 853 & $6.35 \mathrm{E}-04$ \\
\hline & & FN3 & 867 & 943 & $7.45 \mathrm{E}-10$ \\
\hline & & FN3 & 955 & 1039 & 5.04E-07 \\
\hline Col 8 & ENSG00000144810 & $\mathrm{C} 1 \mathrm{Q}$ & 609 & 744 & 3.27E-79 \\
\hline Col 9 & ENSG00000112280 & TSPN & 50 & 244 & $2.02 \mathrm{E}-87$ \\
\hline \multirow[t]{2}{*}{ Col 10} & \multirow{2}{*}{ ENSG00000123500 } & C1Q & 545 & 680 & $6.20 \mathrm{E}-80$ \\
\hline & & TSPN & 38 & 229 & $1.15 \mathrm{E}-68$ \\
\hline \multirow[t]{13}{*}{ Col 11} & \multirow[t]{13}{*}{ ENSG00000060718 } & LamG & 97 & 228 & $9.48 \mathrm{E}-06$ \\
\hline & & COLFI & 1576 & 1805 & $7.39 \mathrm{E}-128$ \\
\hline & & FN3 & 25 & 103 & $1.28 \mathrm{E}-08$ \\
\hline & & VWA & 138 & 317 & $1.21 \mathrm{E}-62$ \\
\hline & & FN3 & 334 & 413 & $1.35 \mathrm{E}-07$ \\
\hline & & VWA & 438 & 617 & $5.62 E-58$ \\
\hline & & FN3 & 632 & 710 & $2.16 \mathrm{E}-06$ \\
\hline & & FN3 & 723 & 801 & $1.74 \mathrm{E}-10$ \\
\hline & & FN3 & 814 & 892 & $6.59 \mathrm{E}-11$ \\
\hline & & FN3 & 905 & 984 & 2.23E-08 \\
\hline & & FN3 & 995 & 1074 & $9.54 \mathrm{E}-08$ \\
\hline & & FN3 & 1087 & 1166 & 4.09E-07 \\
\hline & & VWA & 1197 & 1376 & $3.46 \mathrm{E}-58$ \\
\hline \multirow[t]{12}{*}{ Col 12} & \multirow[t]{12}{*}{ ENSG00000111799 } & FN3 & 1385 & 1463 & $2.46 \mathrm{E}-10$ \\
\hline & & FN3 & 1474 & 1554 & 3.29E-11 \\
\hline & & FN3 & 1566 & 1643 & $9.83 \mathrm{E}-10$ \\
\hline & & FN3 & 1655 & 1734 & 7.63E-07 \\
\hline & & FN3 & 1753 & 1832 & 1.09E-11 \\
\hline & & FN3 & 1844 & 1922 & 4.09E-07 \\
\hline & & FN3 & 1934 & 2013 & $9.69 \mathrm{E}-09$ \\
\hline & & FN3 & 2025 & 2104 & 3.73E-10 \\
\hline & & FN3 & 2116 & 2193 & 7.57E-11 \\
\hline & & FN3 & 2204 & 2283 & 6.35E-04 \\
\hline & & VWA & 2321 & 2501 & $7.09 \mathrm{E}-55$ \\
\hline & & TSPN & 2520 & 2712 & 1.25E-78 \\
\hline
\end{tabular}


Table 2 Contd.

\begin{tabular}{|c|c|c|c|c|c|}
\hline Col 13 & ENSG00000197467 & - & - & - & - \\
\hline \multirow{11}{*}{ Col 14} & \multirow{11}{*}{ ENSG00000187955 } & FN3 & 30 & 108 & 4.22E-09 \\
\hline & & VWA & 156 & 335 & $3.36 \mathrm{E}-56$ \\
\hline & & FN3 & 353 & 433 & 3.32E-07 \\
\hline & & FN3 & 443 & 521 & $6.20 \mathrm{E}-07$ \\
\hline & & FN3 & 535 & 612 & 8.83E-12 \\
\hline & & FN3 & 624 & 703 & 4.77E-08 \\
\hline & & VWA & 1030 & 1210 & 7.53E-59 \\
\hline & & TSPN & 1229 & 1424 & 2.46E-68 \\
\hline & & FN3 & 735 & 817 & $9.25 \mathrm{E}-06$ \\
\hline & & FN3 & 829 & 908 & 1.45E-07 \\
\hline & & FN3 & 919 & 998 & 2.14E-01 \\
\hline Col 15 & ENSG00000204291 & - & - & - & - \\
\hline Col 16 & ENSG00000084636 & TSPN & 50 & 231 & $3.82 \mathrm{E}-74$ \\
\hline Col 17 & ENSG00000065618 & - & - & - & - \\
\hline \multirow{3}{*}{ Col 18} & \multirow{3}{*}{ ENSG00000182871 } & FRI & 333 & 448 & $1.25 \mathrm{E}-25$ \\
\hline & & TSPN & 456 & 644 & $6.32 \mathrm{E}-57$ \\
\hline & & LamG & 505 & 643 & $1.11 \mathrm{E}-01$ \\
\hline \multirow[t]{4}{*}{ Col 19} & \multirow[t]{4}{*}{ ENSG00000082293 } & TSPN & 50 & 234 & $1.01 \mathrm{E}-73$ \\
\hline & & FN3 & 26 & 102 & $1.96 \mathrm{E}-54$ \\
\hline & & VWA & 177 & 356 & 7.66E-51 \\
\hline & & FN3 & 377 & 457 & $1.57 \mathrm{E}-08$ \\
\hline \multirow{5}{*}{ Col 20} & \multirow{5}{*}{ ENSG00000101203 } & FN3 & 466 & 546 & $1.13 \mathrm{E}-09$ \\
\hline & & FN3 & 557 & 636 & $1.55 \mathrm{E}-07$ \\
\hline & & FN3 & 647 & 726 & $2.72 \mathrm{E}-03$ \\
\hline & & FN3 & 741 & 820 & 4.12E-12 \\
\hline & & TSPN & 842 & 1037 & $2.89 \mathrm{E}-33$ \\
\hline \multirow{2}{*}{ Col 21} & \multirow{2}{*}{ ENSG00000124749 } & VWA & 35 & 212 & $3.02 \mathrm{E}-49$ \\
\hline & & TSPN & 230 & 412 & $2.18 \mathrm{E}-19$ \\
\hline \multirow[t]{2}{*}{ Col 22} & \multirow{2}{*}{ ENSG00000169436 } & VWA & 36 & 218 & 3.83E-51 \\
\hline & & TSPN & 239 & 427 & $1.55 \mathrm{E}-33$ \\
\hline Col 23 & ENSG00000050767 & - & - & - & - \\
\hline \multirow[t]{2}{*}{ Col 24} & & TSPN & 68 & 228 & $1.02 \mathrm{E}-05$ \\
\hline & ENSG00000171502 & COLFI & 1514 & 1714 & 3.85E-35 \\
\hline Col 25 & ENSG00000188517 & - & - & - & - \\
\hline Col 26 & ENSG00000160963 & - & - & - & - \\
\hline \multirow{2}{*}{ Col 27} & \multirow{3}{*}{ ENSG00000196739 } & TSPN & 45 & 222 & $1.46 \mathrm{E}-05$ \\
\hline & & OLFI & 1659 & 1860 & $1.41 \mathrm{E}-42$ \\
\hline \multirow{3}{*}{ Col 28} & & VWA & 46 & 228 & 3.06E-18 \\
\hline & \multirow[t]{2}{*}{ ENSG00000215018 } & VWA & 796 & 973 & $3.02 \mathrm{E}-40$ \\
\hline & & $\mathrm{KU}$ & 1070 & 1123 & $1.08 \mathrm{E}-19$ \\
\hline
\end{tabular}




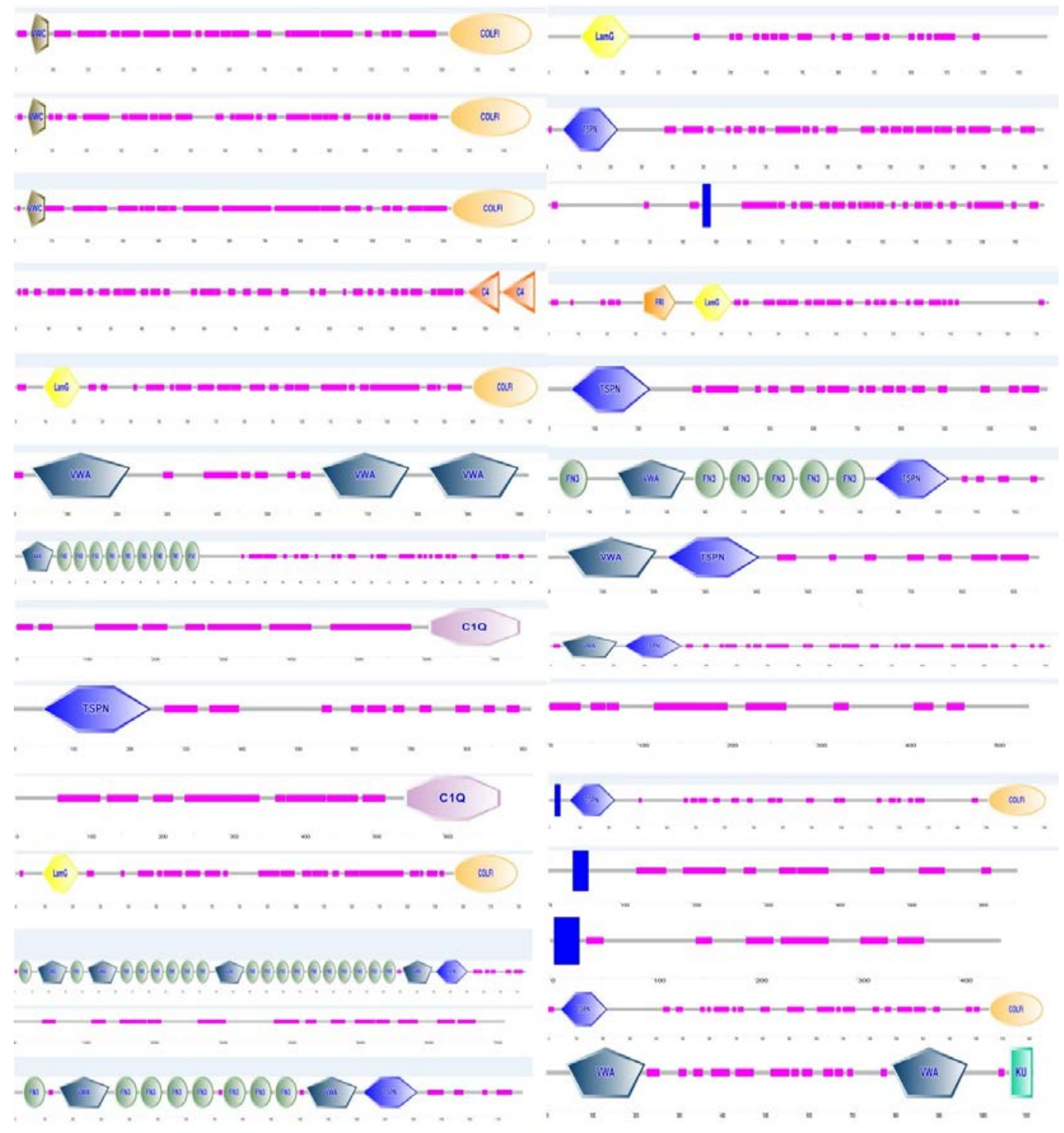

Fig. 2. Protein domain structure of 28 human collagen alpha-1 families.

For the evolutionary study, the phylogenetic analysis shows (Fig. 3a) shows four group of collagen proteins in the 28 family members; the CollXXV and CollXXIII (bright pink), CollXX, CollXII, CollIV (bright green), CollXXVI (red) and rest of the collagen are same groups (blue). In the blue collagen group, there are two different sub-groups CollVI (green) and CollXXVIII (maroon). Hence the CollXXVI is completely separate from the other functional protein groups. Clustering is the unsupervised techniques in machine learning approaches to cluster different groups based on the within groups similarity and between groups dissimilarity. 
For the k-means clustering approach first important issues is the selection of number of $k$; there are several methods exists in the literature for selecting the optimum number of $k$. Scree plot one of them popular methods for selecting $\mathrm{k}$ (Fig. 3b), it was shown two $(\mathrm{k}=2)$ optimum clusters for clustering the amino acid properties. By the $k$-means clustering shown that in different $k=2, k=3, k=4$ (Fig. $3 c$ ) than the finest two functional properties in the amino acid i.e. positively charged and negatively charged. The principal component analysis (PCA) based clustering approach is the modern multivariate techniques. In this paper we used this techniques for identify the joint functional protein complex in the human collagen protein families (Fig. 3d) using biplot; the standardized PC1 is explained $90.6 \%$ and standardized PC2 is $4.9 \%$ with compare the total features. Therefore, the two functional protein complexes are in the human collagen alpha1 proteins. The collagen 12, 14 and 20 are similar protein complex shows the similar properties and rest of the collagens is others group.

The protein-protein interaction network study investigate the jointly and similar functional activity based on the interacting score. The PPI networks analysis (Fig. 4) for identifying the most interacting functional collagen protein groups of 28 human collagen families was done using the STRING database. The top interacting score of Coll12, Coll14 and Coll20 proteins are 0.952, 0.939 and 0.929 respectively (Fig. 5).

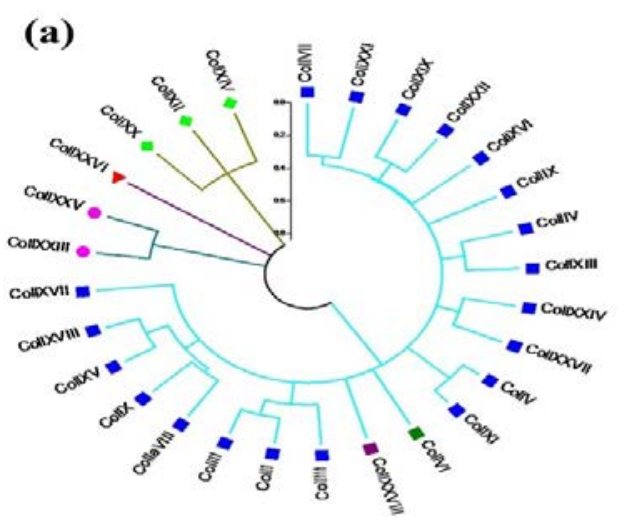

(b)

(c)

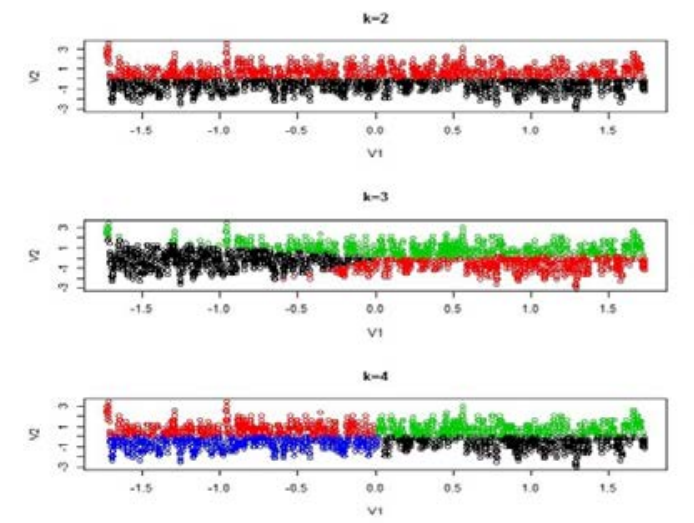

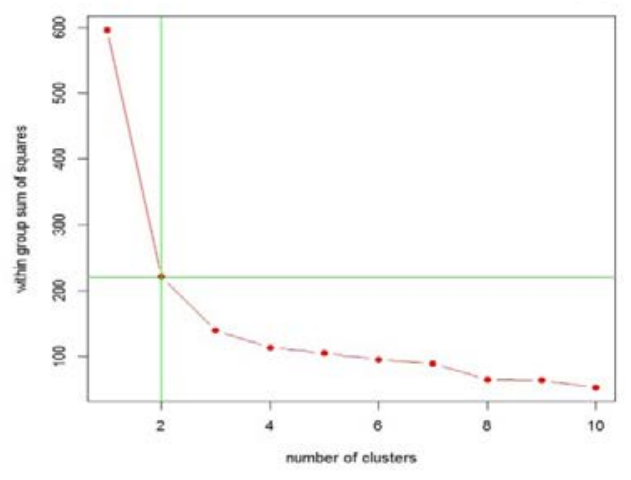

(d)

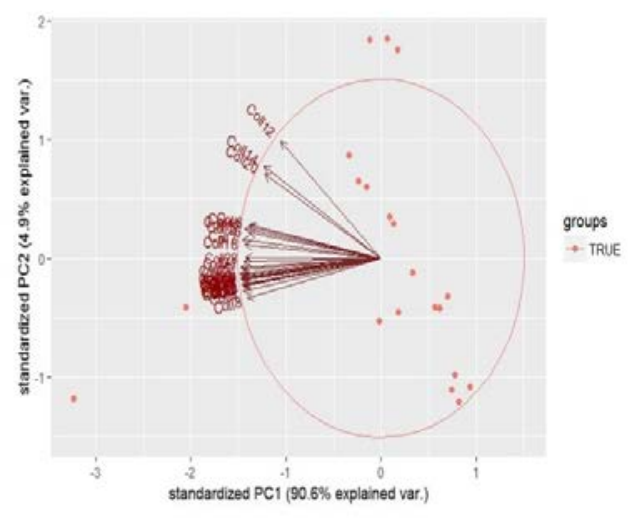

Fig. 3. (a) Phylogenetic tree, (b) Scree plot, (c) K-means clustering and (d) Biplot for the analysis of human collagen family (28) of alpha-1. 

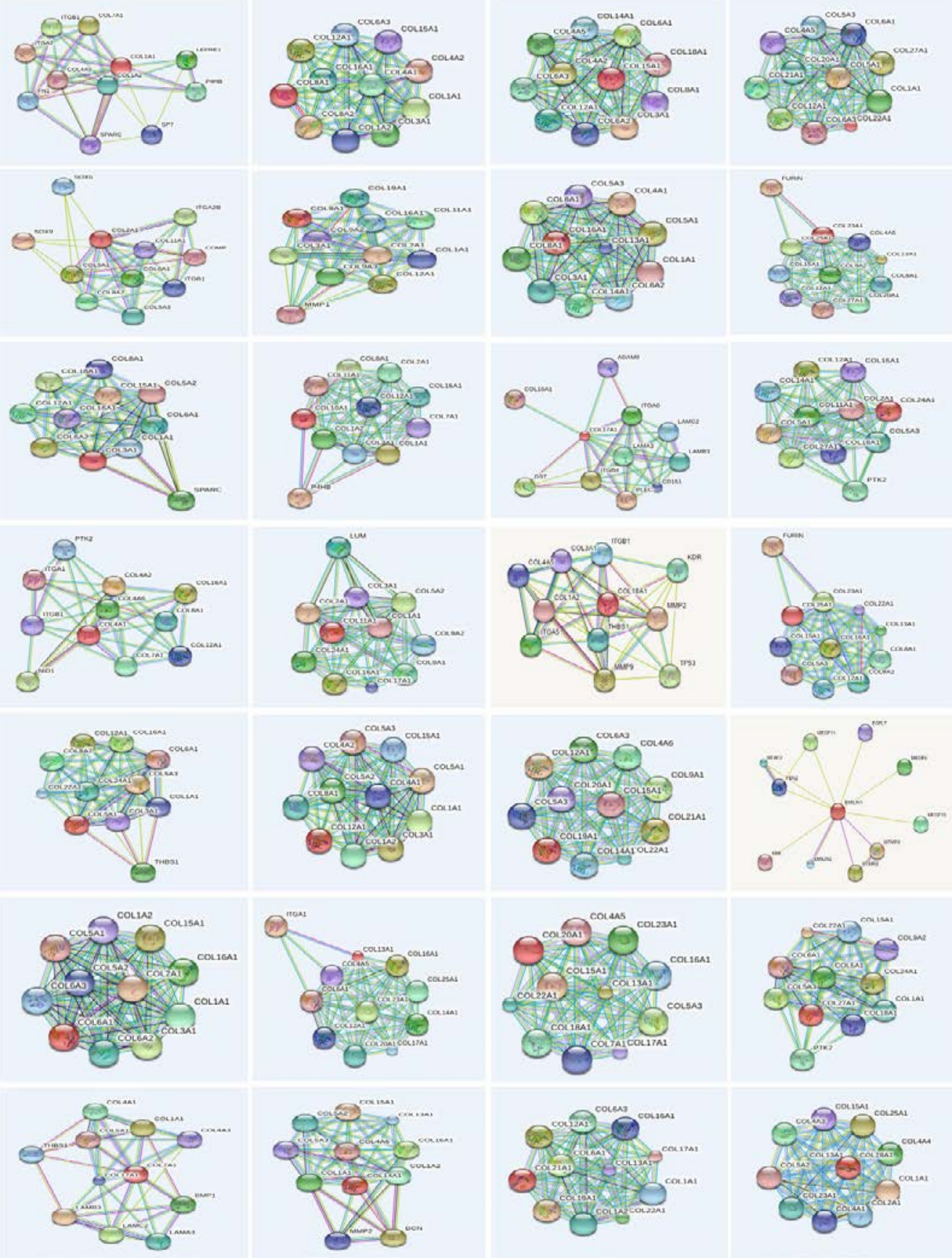

Fig. 4. Protein-protein interaction (PPI) network for finding the most similar functional interacting proteins by the STRING data base of 28 human collagen families. 


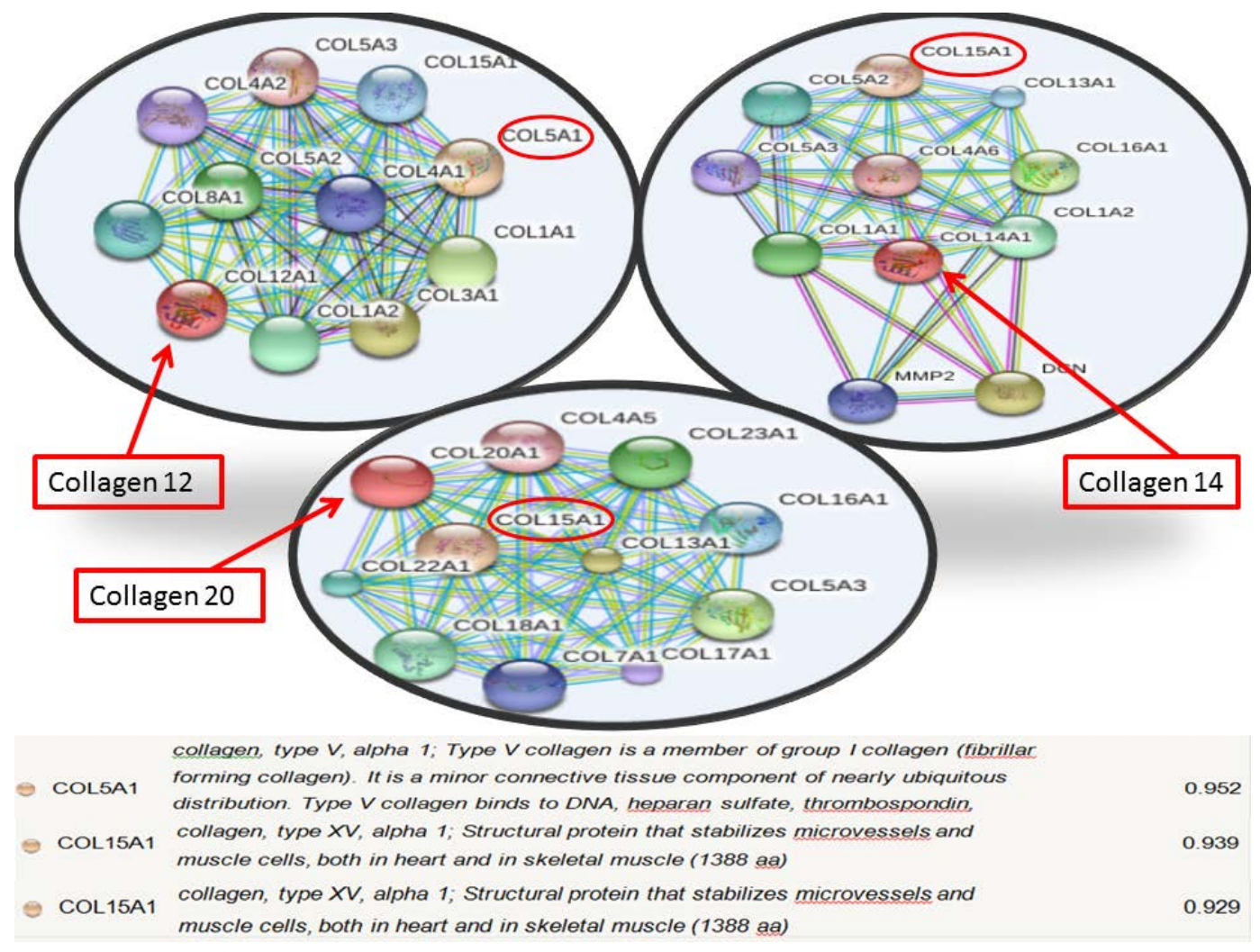

Fig. 5. Protein-protein interaction network for most influential functional interacting group proteins by the STRING data base of Coll12, Coll14 and Coll20 based on the human collagen families.

\section{Conclusion}

The in silico analysis of extracellular matrix proteins is the most important for studying the functional characteristics of human collagen families. The analysis of functional protein domain shows the lots of significant domains are Coll12, Coll14 and Coll20. In this study we used the positively and negatively charged amino acids, that's justify by the screen plot and k-mean clustering approaches. By the principal component analysis approaches it is shown that, the first 2 PC's are explained approximately 95\% out of the total variations. The PC's score plot gives us the two most important functional groups, one of them group collagen proteins are collagen 12, 14 and 20 respectively. The above discussion shown that the most important functional collagen proteins are Coll12, Coll14 and Coll20 based on the several analysis tools including statistical techniques. Those collagens are the FACIT (Fibril Associated collagens with Interrupted Triple helices) group of collagen family. This in silico study is very much helpful for biologist to analysis of the ECM collagen alpha-1 28 protein families of human skin by the reducing the experimental cost, saving consuming time and laborious work in this field. 


\section{References}

Andrea F, Szklarczyk D, Frankild S, Kuhn M, Simonovic M, Roth A, Lin J, Minguez P, Bork P, Mering CV and Jensen LJ (2013). STRING v9.1: protein-protein interaction networks, with increased coverage and integration, Nucleic Acids Research 41: 808-815.

Bairoch A and Apweiler R (2000). The SWISS-PROT Protein Sequence Database and Its Supplement Tr EMBL, Nucleic Acids Research 28(1): 45-48.

Bateman JF, Boot-Handford RP and Lamandé SR (2009). Genetic diseases of connective tissues: cellular and extracellular effects of ECM mutations, Nature Reviews Genetics 10(3): 173-83.

Bowers SL, Banerjee I and Baudino TA (2010). The extracellular matrix: at the center of it all, Journal of Molecular and Cellular Cardiology 48(3): 474-82.

Gelsea K, E Poschlb and T Aignera (2003). Collagens-structure, function, and biosynthesis, Advanced Drug Delivery Reviews 55: 1531-1546.

Ivica Letunic and Bork TDP (2012). SMART 7: recent updates to the protein domain annotation resource, Nucleic Acids Research 40: 302-305.

Järveläinen H, Sainio A, Koulu M, Wight TN and Penttinen R (2009). Extracellular matrix molecules: potential targets in pharmacotherapy, Pharmacological Reviews 61(2): 198-223.

Kadler KE, Holmes DF, Trotter JA and Chapman JA (1996). Collagen fibril formation, Journal of Biochemistry 15(1): 1-11.

Koichiro Tamura, Daniel Peterson, Nicholas Peterson, Glen Stecher, Masatoshi Nei and Kumar S (2011). MEGA5: Molecular Evolutionary Genetics Analysis Using Maximum Likelihood, Evolutionary Distance, and Maximum Parsimony Methods, Molecular Biology and Evolution 28(10): 2731-2739.

Kyte J and Doolittle RF (1982). A simple method for displaying the hydropathic character of a protein, Journal of Molecular Biology 157: 105-132.

Lim KF (2006). Negative pH Does Exist, Journal of Chemical Education 83(10): 1465.

Nassa M, Anand P, Jain A, Chhabra A, Jaiswal A, Malhotra U and Vibha Rani (2012). Analysis of human collagen sequences, Bioinformation 8(1): 026-033. 
Ahmed et al. 